\title{
Algumas premissas à crítica de Nietzsche à teatrocracia
}

\author{
Gianfranco Ferraro*
}

\begin{abstract}
Resumo: Na crítica que desenvolverá em relação a Wagner, Nietzsche aponta para o perigo de uma nova forma de poder, nomeadamente o da teatrocracia de Bayreuth, que pode ser interpretada, na senda das reflexões de Benjamin, Debord e Agamben, como o exórdio daquela forma de representação estética do domínio político chem durante todo o século XX, dará vida a novas formas de mitologia política. Nietzsche contrapor-lhe-á uma forma de "escrita trágica" inspirada, nos anos da juventude, ao tema hölderliniano da morte de Empédocles: uma fidelidade que, através do Zarathustra, voltaremos a encontrar até nos últimos escritos de Nietzsche: Ecce Homo e as cartas da "loucura".

Palavras-chave: teatrocracia - representação - Empédocles - Hölderlin - teologia politica
\end{abstract}

A reproposição de um Nietzsche totus politicus, precursor, se já não do nacionalsocialismo, ao menos desse "relativismo epistemológico" hoje criticado em nome de novas, embora muitas vezes bastante indefinidas, formas de positivismo filosófico ${ }^{1}$, impõe hoje uma reflexão sobre as contribuições efetivas que o pensamento nietzschiano ofereceu à reflexão política das últimas décadas, sem deixar por isso de sondar as possibilidades teóricas abertas pelos seus textos. Pretendemos apresentar aqui, no âmbito de um estudo mais abrangente que se moveu em torno à crítica desenvolvida por

\footnotetext{
* Pós-doutorando no Instituto de Filosofia da Linguagem da FCSH da Universidade Nova de Lisboa, Portugal, e colaborador nas Universidades de Pisa e della Calabria, Itália, no âmbito do Centro “Colli-Montinari”. Endereço eletrônico: gianfranco.ferraro@gmail.com.

1 No contexto italiano, adquiriu tal colocação a chamada corrente do "new realism", que nasce do encontro entre os últimos herdeiros do "pensamento fraco" e um renovado interesse pelas correntes filosóficas analíticas e pragmatistas de proveniência anglosaxónica.
}

Cad. Nietzsche, São Paulo, n. 34 - vol. I, p. 151-163, 2014. | 151 
Ferraro, G.

Nietzsche à teatrocracia, a forma daquela raiz "espetacular" do poder moderno sobre a qual refletiram Benjamin, Debord e, mais recentemente, Giorgio Agamben, com a análise de algumas das premissas dessa crítica. Antes ainda de se fazer interprete da tragédia e do papel da tragédia na antiguidade clássica e na modernidade, Nietzsche, seguindo de perto o autor mais amado na sua juventude, Friedrich Hölderlin, pena-se ele próprio como escritor trágico, esboçando alguns rápidos esquemas de uma tragédia dedicada a Empédocles, o filósofo que, conforme o relato de Diógenes Laércio, para se contrapôr à forma de autoridade tiránica que o povo de Agrigento quereria atribuir-lhe, decide sacrificar-se atirando-se no Etna. Seguiremos portanto uma pista, ou seja a que o sujeito de Empédocles traçou na biografia da juventude de Nietzsche, para verificar quão radicada esteja, nesta altura cronológica, a conciência do papel crítico do "filósofo trágico" perante a cena política que ele próprio "representa": evidente, aliás, como, no Zarathustra e em Ecce Homo - "a minha humanidade é uma contínua vitória sobre mim mesmo" - o superamento do si, e da própria forma, através de uma escrita trágica do si, torna-se justamente o cerne dessa filosofia trágica, que já há algum tempo, em 1888, contrapunha-o aos presupostos "tiránicos" da música wagneriana.

1. "A teatrocracia - afirmou recentemente Giuliano Campioni - é a cenografia necessária para chegar a um poder tiránico que não tolera, ao seu lado, os outros, se não servos"2. Na sua crítica a Wagner e ao Gesamtkunstwerk wagneriano (Richard Wagner a Bayreuth), como sabemos, Nietzsche incluirá aquela parte da própria obra anterior ao grande conflito com o músico. Mas o que é que

2 Nietzsche: $i$ segni dell'opera, le tracce dell'uomo. Intervista di Gianfranco Ferraro a Giuliano Campioni. In: FERRARO, G., FORNARI, M. C. (orgs.). Chi ha veramente letto Nietzsche? Firenze: «Il Ponte», anno LXIX, nn. 8-9, Agosto-Settembre 2013, p. 140. Cf. também BARBERA, S., CAMPIONI, G., Il genio tiranno: ragione e dominio nell'ideologia dell'Ottocento. Wagner, Nietzsche, Renan. Pisa: ETS, 2010.

152 I Cad. Nietzsche, São Paulo, n. 34 - vol. I, p. 151-163, 2014. 
está em jogo nessa crítica senão justamente a diferença entre uma relação política fundada na subjugação à fictio, e uma relação política que se instaura, ao contrário, no momento em que se cria uma "cena trágica", ou seja a relação que o próprio Nietzsche pretende instaurar com o seu leitor: um "teatro do conhecimento"?

O que Nietzsche criticará ao Wagner sacerdote das liturgias de Bayreuth é evidentemente a afirmação "tiránica" de um domínio determinado justamente do artifício, da fictio, de uma cena. A afirmação desta ficção constitui a afirmação de uma relação de domínio sobre o público: sobre uma comunidade mitológica em que uma forma de domínio é legitimada pela música com modalidades novas, cuja estética - Agamben recentemente falou, a este respeito, de uma forma "gloriosa" do Reino ${ }^{3}$ - aceitáveis depois da secularização imposta pelo colapso do Ancien Régime. A crítica de Nietzsche a Wagner é portanto também uma crítica a uma mitologia do trágico que trai o próprio fundamento conflitual, para se desenvolver, justamente como teatrocracia, na afirmação de relações de poder de carácter estético que se estabelecem através das que poderíamos chamar de processos secularizados de liturgia. É justamente neste sentido que a crítica nietzschiana à teatrocracia wagneriana, grande precursora dessas formas de construção da mitologia do político que logo o séc. XX herderá, implica de per si uma crítica muito atual às formas mais penetrantes de legitimação do poder político.

No Natal de 1888, concluíndo a cansativa e solitária maratona de escrita que o levará, daí há uma dezena de dias, à loucura, Nietzsche assina o prefácio a uma obra, Nietzsche contra Wagner, que por sua explícita vontade decidirá, porém, de não publicar. Obra que todavia, já desde o seu subtítulo, "Documentos Processsuais de um Psicólogo", pretende clarificar desde logo a direcção para a qual Nietzsche está movendo-se. É enquanto psicólogo que

3 Cf. AGAMBEN, G.., Il Regno e la Gloria. Per una genealogia teologica dell'economia e del governo. Homo sacer, II, 2, Vicenza: Neri Pozza, 2007. 
Ferraro, G.

o filósofo pretende se confrontar mais uma vez com o seu grande alter-ego, e explicitar os caminhos pelos quais ele chegou à sua posição em relação à Musikdrama de Wagner. Estamos portanto perante uma espécie de anámneses, ou, para utilizar a metáfora interna ao texto de Nietzsche, a exposição que a acusa faz perante o juíz das provas que sustentam as suas teses de condena do imputado, tese que é logo explicitada: «Nós somos antípodas» [NW/NW, Prefácio, KGW VI,3, S. 413]4. "Dar as costas a Wagner foi para mim um destino» escreve Nietzsche em $O$ Caso Wagner, interrogando-se acerca do que realmente tinha sido este trabalho de condena e superamento do wagnerismo. Nietzsche dá uma resposta: tratou-se «Talvez de um superamento de si». «O que é que em primeiro e último lugar exige um filósofo de si mesmo? Superar dentro de si o próprio tempo, tornar-se 〈sem-tempo〉. Com o que, portanto, o filósofo tem de sustentar a sua mais dura luta? Justamente com a coisa em que ele é filho do seu tempo. Ora, eu sou tanto quanto Wagner, o filho desse tempo, ou seja, um décadent: só que eu entendi-o, e contro isso me defendi. O filósofo, dentro de mim, defendeu-se de tudo isto" (WA/CW Prefácio, KGW VI,3, S. 3).

A encenação deste combate é portanto representação plástica das próprias forças que animam a decadência. Das forças que se agitam e se contrapõem até no próprio indivíduo: neste sentido, a doença torna-se um momento determinante para o reconhecimento de tais forças. O filósofo, a sua própria biografia, manifestam-se então como a "cena", por assim dizer, em que este combate tem lugar, em que se pode reconhecer a doença, e consequentemente a sua cura. Por isso Wagner, afirma Nietzsche, é indispensável

4 A expressão aparecerá num escrito de Montinari dedicado ao último encontro, que se deu em Itália 1876, entre o filósofo e o músico. Passados apenas dois anos, em 1878, a separação dos dois caminhoss torna-se definitiva, quando, como Nietzsche dirá em Ecce Homo, ao envio para Wagner do texto de Humano demasiado Humano, seguirá de poucos dias a recepção por parte do filósofo do texto do Parsifal: «Para além da lenda fica um facto: o Wagner do Parsifal era o antípoda do Nietzsche»: MONTINARI, M., Nietzsche e Wagner cent'anni fa, em Su Nietzsche. Roma: Editori Riuniti, 1981, p. 15.

154 I Cad. Nietzsche, São Paulo, n. 34 - vol. I, p. 151-163, 2014. 
para o filósofo moderno. "Através de Wagner, a modernidade fala a sua mais íntima linguagem: não esconde nem o seu bem nem o seu mal, desaprendeu qulaquer pudor de si mesma. Viceversa, conseguimos chegar quase a um balanço do valor da modernidade quando, dentro de si, fez-se luz sobre bem e o mal de Wagner" (WA/CW, Prefácio, KGW VI,3, S. 3). Escreveu Giorgio Colli a este respeito, pensando também a estas páginas:

O que se manifesta em Wagner, o ilusionismo que fagocita todo o resto da vida para o seu próprio benefício, a falsificação, a contrafação, o dar cabo premeditado de qualquer arquétipo interior, de qualquer leveza, de qualquer jogo, de qualquer forma, a exaltação do obscuro, do turvo, do macio, contra cada luminosidade e mesura, em suma tudo o que a arte depois de Wagner recolheu e aplicou, não conseguíu, neste último século, exprimir nada, não digo só de mais válido, mas nem sequer de mais conforme o seu objectivo, em relação a o que expressara o próprio Wagner 5 .

Neste drama da redenção, na reproposição generalizada da missa solemnis que finalmente o Parsifal possibilita, o drama wagneriano manifesta-se como encenação da fé, «banir de cada investigação e de cada pergunta»: máquina de sentido e de redenção aliás bem aceite pelo seu público, e até pelo refinado público parisiense, pois, na décadence, vai naturalmente ao encontro de uma cada vez mais comum vocação à "servidão voluntária": a redução ad unum da multiplicidade eterogénea de forças ${ }^{6}$. No fim da sua parábola, Nietzsche identificará na crítica a uma tal encenação, um traço de fidelidade característico do seu pensamento já desde os seus exórdios.

5 COLLI, G.., Dopo Nietzsche, Milano: Adelphi, 1974, p. 119.

6 Escreve a este respeito Montinari: "Mas Bayreuth representa, na visão provocatória de Nietzsche, também uma derrota para todo o sistema de cultura e educação da sociedade contemporânea, e se os intelectuais irão finalmente reparar na podridão desse sistema, ele ficará sem um apoio substancial": MONTINARI, M., op. cit., p.18. 
Ferraro, G.

Justamente nos exórdios da sua carreira, pensamos poder identificar, num Nietzsche ainda estudante, algumas das premissas, se já não da crítica que ele desenvolverá só depois $O$ Nascimento da Tragédia, ao menos àquela fundamental "fidelidade".

2. A presença do nome de Hölderlin entre as cartas de Nietzsche tem que ser portanto colocada na época dos seus estudos liceais. É de facto num esboço de carta de 1861 destinada a Gustav Krug e Wilhelm Pinder que encontramos pela primeira vez o nome do poeta alemão, mas é em outra carta, essa destinada a Rohde, e escrita quando, em Setembro de 1869 Nietzsche é já um jovem filólogo de fama, que ele confessa como Hölderlin tenha sido um dos autores preferidos da sua adolescência. Ora, bastante depois dessa paixão hölderliniana testemunhada pelos textos de juventude, Nietzsche acaba por escolher justamente Empédocles, ou melhor, a morte do filósofo pré-socrático, já argumento de três redações de uma tragédia por parte de Hölderlin, para além do seu conhecido poema, como argumento próprio de escrita trágica. Poderíamos talvez acrescentar que Nietzsche alcance este tipo de escrita trágica como através o esforço de esclarecimento em relação à sua própria reflexão. Como se, em suma, só ao encenar o problema teórico, isto é, ao seguir o mesmo caminho de Empédocles, que constitui no fundo o fil-rouge de $A \mathrm{Fi}$ losofia na Época Trágica dos Gregos, como do mesmo Nascimento da Tragédia, se pudesse conseguir, efetivamente, fazer prática do pensamento trágico. Empédocles aparenta ser, nestes trechos, o filósofo que se liberta da estreiteza do mito e da teologia política, para experimentar, na sua pele, a fatiga do conhecimento. A peste, relatada por Diógenes Laércio na senda do mito, e retomada por Hölderlin, torna-se símbolo da inevitabilidade da decadência perante a qual o antigo filósofo é apresentado como o homem da redenção possível (cf. NF-1870,8[30], KGW, III,3, S.244). Enquano a potência da infeção manifesta-se em cheio, Nietzsche define em que termos dá-se a viragem da tragédia, isto é, a Zäsur [cesura]. O calafrio que Empédocles experimenta perante a natureza, é a premissa ao que

156 I Cad. Nietzsche, São Paulo, n. 34 - vol. I, p. 151-163, 2014. 
acontecerá mal a cena muda de sentido: o último dia de festa parece estar dedicado a uma cerimónia religiosa tradicional em cujo centro encontramos o deus Pã, que, durante um sacrifício humano ritual, teria de ser sacrificado no Etna. Mas é justamente agora, enquanto o povo lança as suas maldições, que Empédocles “im Übermaß des Mitleids" (KGW, III,3, S.244), decide substituir-se-lhe no lugar da vítima sacrifical. A tragédia é portanto nesta página a representação da substituição da vítima para a salvação da cidade. O fim último, o de curar a cidade, é confirmado também em fragmentos posteriores, junto com a vocação sacrifical de Empédocles, até nos em que ele parece já desencorajado em relação a este intuito, do momento em que a cidade parece irremediavelmente decaída, "abgefallen" (KGW, III,3, S.244), em relação à forma de vida grega. Impressiona a consequencialidade através da qual Nietzsche define programaticamente a concatenação entre vontade de redenção de Empédocles em relação à cidade, e o seu próprio destino:

In seiner Göttlichkeit will er helfen.

Als mitleidiger Mensch will er vernichten.

Als Dämon vernichtet er sich selbst.

Immer leidenschaftlicher wird Empedokles

(KGW III,3, S.244).

Entretanto vai-se compondo o esquema dos personagens que acompanha de perto um esquema já presente em Hölderlin, com a presença de Corina e de Pausânias, do povo, figura colectiva com o povo e com os camponeses, e com a figura do padre, ou seja do sacerdote do culto de Pã. No fragmento 8[37] (cf. KGW III,3, Ss.246-247) encontramos finalmente o primeiro esquema da tragédia, desde a subdivisão em dois actos, a repartição evolve para um esquema constituído por cinco partes. Aliás essa estrutura parece aderir de forma calculada a um balançamento simétrico em que a função de eixo é jogada pelo terceiro acto que vê no seu centro o coro e o aparecimento de Dioniso. Na primeira cena o medo 
Ferraro, G.

à peste é dominante, enquanto na segunda vem a manifestar-se, juntamente, o papel sacerdotal e político de Empédocles: perante o medo pelo qual a cidade é perpassada - poderíamos até dizer que é mesmo o medo a ser aqui o sentimento crucial - Empédocles encena a tragédia: ele mesmo não é apenas filósofo, mas também tragediógrafo. È porém no acto quinto que Nietzsche define os caraterísticos do seu personagem: aqui, de facto, Empédocles adsquire definitivamente, para si, os característicos da vítima designada ("fühlt sich als Mörder"), na esperança ("er hofft...") que da morte expiatória possa por fim surgir uma renascença. A cena é por um istante interrompida por uma pedido, avançado talvez pela própria Corina, para convencer o amado a deixá-la sacrificar-se junto com ele, ou talvez, de forma impessoal (pelo coro?) para evidenciar a necessidade do gesto. "Flieht Dionysus vor Ariadne?". O laço entre Corina e Empédocles, enquanto presença da figura dos amantes na representação trágica (cf. também 5[117], KGW III,3, S.129) $)^{7}$, recalca o entre os dois personagens do mito, mas o que não pode escapar-nos, aqui, é, evidentemente, a identificação de Empédocles com o próprio Dioniso. No esquema seguinte, em que podemos encontrar o esboço de uma reflexão acerca do horizonte do espírito trágico, Nietzsche define finalmente o próprio home trágico como «die Natur in ihrer höchsten Kraft des Schaffens und des Erkennens und deshalb mit Schmerzen gebärend: Die Menschen sind meist nach einer Seite hin ausgeartet, selbst bei höchsten Talenten»(KGW III,3, S.123). Num esquema sucessivo (Cf. NF-1870,5[116], KGW III,3, S.129) encontramos a explicitação do risco político intrínseco ao papel religioso adquirido pelo trágico. Aqui Nietzsche esboça a tentativa dos cidadãos de Agrigento de coroar Empédocles tirano da cidade. Ao mesmo tempo explicita-se aqui também a razão da sua recusa: “Er erkennt den Wahn der

7 "Das Weib in der Theatervorstellung, stürzt heraus und sieht den Geliebten niedersinken. Sie will zu ihm, Empedokles hält sie zurück und entdeckt seine Liebe zu ihr. Sie giebt nach, der Sterbende spricht, Empedokles entsetzt sich vor der ihm offernbarten Natur".

158 I Cad. Nietzsche, São Paulo, n. 34 - vol. I, p. 151-163, 2014. 
Religion, nach langem Kampf". Aqui a figura do padre permanece no pano de fundo, enquanto Nietzsche prefere evidenciar a batalha conduzida pela natureza trágica contra a loucura da religião. Se neste fragmento o sacrifício de Empédocles é ausente, em seu lugar porém, na conclusão da representação, ecoa o grito que marca o fim da Antiguidade: "o grande Pã é morto".

Excepção feita por uma breve e parcial reproposta do argumento de Empédocles num fragmento posterior de cerca de dois anos, as tentativas de Nietzsche de elaborar uma tragédia, tendo como argumento Empédocles, ficam por aqui ${ }^{8}$.

O nome do pré-socrático a partir deste momento voltará a aparecer nos escritos preparatórios a A Filosofia na Época Trágica dos Gregos, com o dos outros filósofos trágicos que precedem Sócrates. Empédocles voltará a aparecer em Richard Wagner a Bayreuth [WB, 4]: aqui Nietzsche, numa das passagens em que, da forma mais explícita, evidencia o aspecto da sua antropologia cultural segundo o qual as culturas também progridem por contínuas gemações, aspecto que posteriormente será aprofundado, sublinha como alguns quadros culturais e filosóficos próprios da antiguidade, possam ser propostos novamente num contexto moderno. Então, uma vez reduzida a influência do cristianismo, escreve Nietzsche, a força aplacada da civilização grega volta a comparecer: eis que então assistimos "a fenómenos tão surpreendentes, que vagariam no ar inesplicáveis, se não pudêssemos ligá-los, superando um enorme espaço de tempo, com as analogias gregas. Assim entre Kant e os

8 No fragmento mencionado Nietzsche questiona a relação de contingência com a própria existência de que os gregos da época trágica fariam experiência, embora capazes de pensar as suas próprias obras para além dessa contingência, ao contrário do que fará o "decadente" Strauss, que escreve obras destinadas a morrer em breve, comportando-se como se tivesse de sobreviver-lhes: "Empedokles sagte den Agrigentinern nach: sie hingen den Lüsten an, als ob sie den anderen Tag sterben sollten, und sie bauten so, als ob sie niemals sterben würden. Strauß baut so, als ob sein Buch morgen sterben müßte, und benimmt sich so, als ob es gar niemals sterben sollte" [KGW III,4, S.205]. Neste sentido Empédocles torna-se aqui o símbolo por excelência do anti-decadente. 
Ferraro, G.

eleáticos, entre Schopenhauer e Empédocles, ou entre Ésquilo e Richard Wagner, existem proximidades e afinidades tais [solche Nähen und Verwandtschaften], que a natureza muito relativa de todos os conceitos de tempo é-nos quase tangivelmente relembrada" [WB, 4, KGW IV,1, S.18]. Mas evidenciar analogias e diferenças entre mundos culturais temporalmente tão distantes, serve outrossim para investigar as persistências e as linhas de continuidade através das quais as formas culturais dialogam. Aliás para Nietzsche, neste sentido discípulo de Hölderlin, é justamente a estrutura trágica a ter por intuito o de deixar emergir, perante o desencadeamento incontrolável das forças históricas, um novo mundo, ou seja uma nova pátria. A tragédia torna-se neste sentido a forma de expressão simbólica das forças que dominam incontroláveis o cenário da polis, como lembra Christian Meier no seu ensaio sobre a arte política da tragédia grega ${ }^{9}$. Assim a dissolução do herói trágico, sublinhada por Szondi no seu Ensaio sobre o Trágico, será o que ao mesmo tempo, reduzindo $=0$ a expressão simbólica, possibilita a manifestação da natureza.

3. Numa das últimas frases que Nietzsche escreverá ainda lúcido, na conclusão de Ecce Homo, "Hat man mich verstanden? -Dionysos gegen den Gekreuzigten..." (EH/EH, Porque sou um destino, 9, KGW VI,3, S.372), estamos em presença de uma substituição sacrifical. O próprio sentido da ostensão do corpo biográfico do autor está compreendido no facto que ao antigo deus, está a ser substituído o novo, Dioniso, deus de Zarathustra ${ }^{10}$. No seu derradeiro ano de vida Nietzsche obedeceria "à suicida vontade de verdade que reconhecera como vontade adversa à vida, como distruição da

9 Cf. MEIER. Die politische Kunst der griechischen Tragödie, München: C. H. Beck'sche Verlagbuchhandlung, München 2000.

10 Cf. LUPO, L., Appena prima del buio. Le lettere di Nietzsche da Torino. Em CAMPIONI, G.., - PICA CIAMARRA, L., SEGALA, M., (org.). Goethe Schopenhauer Nietzsche. Saggi in memoria di Sandro Barbera, Pisa: ETS 2011, pp. 463-472.

160 I Cad. Nietzsche, São Paulo, n. 34 - vol. I, p. 151-163, 2014. 
própria vida"11. Corresponendo a uma tal vocação, o filósofo parece então progressivamente debruçar-se em direção a uma atuação literal do seu próprio pensamento, que, como tal, não pode não ser também atuação da distinção do ser que deu forma a esse pensar.

Retraíndo-se da sua própria identidade, e multiplicando-a, até assinar-se também, alternativamente, Dioniso ou O Crucifixo, Nietzsche parece, por assim dizer, ter feito uma experiência, experiência sobre a doença que constitui, no fundo, a própria trama de Ecce Homo, e que o tornou ao mesmo tempo "décadent e começo". Mas Ecce Homo, como representação desta experiência, não escapa à lógica, interna a escrita trágica, que já vimos em ação no jovem Nietzsche e que de forma certamente mais complexa, operará em Assim Falou Zarathustra. Uma lógica que se opõe àquela teatrocracia wagneriana que neste sentido resultará ser - e em Nietzsche contra Wagner teremos ainda um último testemunho deste contraste sem saída - a forma mais acabada da antiga tirania. Uma mise en forme da economia da redenção a que evidentemente se opõe uma outra economia da redençaõ: a do filóssofo trágico. O nome de Empédocles naturalmente já desapareceu, mas não desapareceu a intentio trágica de Nietzsche: "Eu prometo uma época trágica: a arte suprema de dizer sim à vida, a tragédia, voltará a nascer quando a humanidade terá atrás de si a conciência das guerras mais duras, mas mais necessárias, sem sofrer por ela" (EH/EH, O nascimiento da tragedia, 4, KGW VI,3, S.311). Em Nietzsche não há nem a glória do tirano nem a do fundador de religiões, assim como não há profecia na sua promessa. "Não quero ser um santo, mais depressa um bobo... Talvez seja um bobo... não obstante, aliás, não não obstante - pois até agora nada houve mais mentiroso dos santos - a verdade fala em mim" [EH, Pour que sou um destino, I, KGW VI,3, S.363]. Mas a verdade, como prática autêntica da filosofia,

11 CALASSO, R. Monologo fatale. In: NIETZSCHE, F., Ecce homo. Come si diventa ciò che si è (a cura e con un saggio di R. Calasso), Milano: Adelphi 2005, pp.151-202: p. 193. 
implica justamente a cesura que esvazia a cena da construção teatrocrática. Como escreve Philippe Lacoue-Labarthe, a respeito da decisão hölderliniana de reinterpretar por fim a escrita trágica dedicando-se à tradução de Sófocles, este "regresso ao fundamento da teatralidade" $" 12$, joga-se todo a partir do falhanço do projecto sobre o Empédocles, e a partir precisamente do seu «defeito de teatralidade». Ou seja, A Morte de Empédocles de Hölderlin teria nascido e ter-se-ia desenvolvido a partir de uma substancial não-representabilidade. Por esta razão Hölderlin acabará por abandonar a tragedia depois das três redações. É lá onde Nietzsche concebe a sua escrita como a de um filósofo trágico, que uma nova economia da redenção, programaticamente sem fundamento, parece responder, à distância, ao apelo que o teatro de Hölderlin dirige à cultura alemã.

\begin{abstract}
In his critics towards Wagner, Nietzsche suggests that a new form of power is appearing, as a danger, in Bayreuth's theatrocracy. On the basis of analysis like Benjamin's, Debord's and Agamben's ones, we can look at Bayreuth's theatrocracy as the beginning of a modern, aesthetic representation of power: and during all 20th Century, many forms of political mythologies will appear as marked by this inheritance. As known, Nietzsche will oppose it a "tragic writing", which is inspired, when he is still a young student, to Hölderlin's topic of Empedocles' Death. Across Zarathustra, we can find his adhesion to a "tragic writing" also in his last works, as Ecce homo, and in his Letters of "insanity" too.
\end{abstract}

Keywords: theatrocracy - representation - Empedocles - Hölderlin - political theology

12 LACOUE-LABARTHE, Ph., Le théâtre de Hölderlin. Em Métaphrasis suivi de Le théâtre de Hölderlin, Paris: PUF 1998, p.47 (nossa traduçao). 


\section{referências bibliográficas}

AGAMBEN, G.., Il Regno e la Gloria. Per una genealogia teologica dell'economia e del governo. Homo sacer, II, 2, Vicenza: Neri Pozza, 2007.

BARBERA, S., CAMPIONI, G., Il genio tiranno: ragione e dominio nell'ideologia dell'Ottocento. Wagner, Nietzsche, Renan. Pisa: ETS, 2010.

CALASSO, R., Monologo fatale. Em NIETZSCHE, F., Ecce homo. Come si diventa ciò che si è (a cura e con un saggio di R. Calasso), Milano: Adelphi, 2005, pp.151-202.

COLLI, G. , Dopo Nietzsche, Milano: Adelphi, 1974.

FERRARO, G., FORNARI, M. C. (a cura di), Chi ha veramente letto Nietzsche?, Firenze: «Il Ponte», anno LXIX, nn. 8-9, Agosto-Settembre 2013.

LACOUE-LABARTHE, Ph., Le théâtre de Hölderlin. Em Métaphrasis suivi de Le théâtre de Hölderlin, Paris: PUF, 1998.

LUPO, L., Appena prima del buio. Le lettere di Nietzsche da Torino. Em CAMPIONI, G.., PICA CIAMARRA, L., SEGALA, M., (a cura di), Goethe Schopenhauer Nietzsche. Saggi in memoria di Sandro Barbera, Pisa: ETS, 2011, pp. 463-472.

Cf. MEIER, Die politische Kunst der griechischen Tragödie, München: C. H. Beck'sche Verlagbuchhandlung, 2000.

MONTINARI, M., Nietzsche e Wagner cent'anni fa, em Su Nietzsche, Roma: Editori Riuniti, 1981.

Artigo recebido em 14/05/2013.

Artigo aceito para publicação em20/06/2013.

Cad. Nietzsche, São Paulo, n. 34 - vol. I, p. 151-163, 2014. | 163 